\title{
Butters rich either in trans-10-C18:1 or in trans-11-C18:1 plus cis-9, trans-11 CLA differentially affect plasma lipids and aortic fatty streak in experimental atherosclerosis in rabbits
}

\author{
A. Roy ${ }^{1,2}$, J.-M. Chardigny ${ }^{1 \dagger}$, D. Bauchart ${ }^{2}$, A. Ferlay ${ }^{2}$, S. Lorenz ${ }^{2}$, D. Durand ${ }^{2}$, D. Gruffat ${ }^{2}$, \\ Y. Faulconnier ${ }^{2}$, J.-L. Sébédio ${ }^{1}$ and Y. Chilliard ${ }^{2}$
}

${ }^{1}$ INRA, UMR 1019, Clermont Ferrand, F-63009 France; CRNH Auvergne, Clermont-Ferrand, F-63009 France; ${ }^{2}$ Herbivore Research Unit, INRA, UR1213 Herbivores, Site de Theix, F-63122 St-Genes Champanelle, France

(Received 4 July 2006; Accepted 24 October 2006)

\begin{abstract}
Dairy fat contains high amounts of saturated fatty acids (FA), which are associated with cardiovascular disease (CVD) risk. Manipulation of dairy cows nutrition allows to decrease the saturated FA content of milk fat, and is associated with increases either in conjugated linoleic acid (CLA) and trans-11-C18:1 contents, or in trans-10-C18:1 content. CLA putatively exhibits beneficial properties on CVD risk, whereas trans FA are suspected to be detrimental. The present study compared the effects of a trans-10-C18:1-rich butter (T10 butter), a trans-11-C18:1 + CLA-rich butter (T11-CLA butter) and a standard butter (S butter) on lipid parameters linked to the CVD risk and fatty streaks. Thirty-six White New Zealand rabbits were fed one of the three butters (12\% of the diet, plus $0.2 \%$ cholesterol) for 6 (experiment 1) or 12 (experiment 2) weeks. Liver lipids, plasma lipids and lipoprotein concentrations (experiments 1 and 2) and aortic lipid deposition (experiment 2) were determined. The T10 butter increased VLDL-cholesterol compared with the two others, and total and LDL-cholesterol compared with the T11-CLA butter ( $\mathrm{P}<0.05)$. The T10 butter also increased non-HDL/HDL ratio and aortic lipid deposition compared with the T11-CLA butter $(\mathrm{P}<0.05)$. The T11-CLA butter non-significantly reduced aortic lipid deposition compared with the $S$ butter, and decreased HDLcholesterol and increased liver triacyglycerols compared with the two other butters $(\mathrm{P}<0.05)$. These results suggest that, compared with the $S$ butter, the T10 butter had detrimental effects on plasma lipid and lipoprotein metabolism in rabbits, whereas the T11-CLA butter was neutral or tended to reduce the aortic lipid deposition.
\end{abstract}

Keywords: atherosclerosis, butter, conjugated linoleic acid, rabbits, trans-10-C18:1

\section{Introduction}

The fatty acid (FA) composition of bovine milk fat is of growing interest, since it is typically rich in saturated FA (particularly $C_{12: 0}$ to $C_{16: 0}$ ) which, compared with unsaturated $F A$, are known to elevate plasma total and low density lipoprotein-cholesterol (LDL-C) concentrations (Nicolosi et al., 1997), and thus, the risk of cardiovascular disease (CVD) (Libby et al., 2000). However, milk fat also contains specific FA, as conjugated linoleic acids (CLA) of which cis9, trans- 11 is the major isomer (ca. $0.5 \%$ of total FA and more than $90 \%$ of total CLA). It has been shown to exhibit in animal studies beneficial health effects on cancer prevention and treatment, and cardiovascular risk (reviewed by Wahle et al. (2004)). Chemically synthesised CLA (cis-9,

\footnotetext{
${ }^{\dagger}$ Corresponding author. E-mail: chardign@clermont.inra.fr
}

trans-11 CLA or mixture of cis-9, trans- $11+$ trans-10, cis-12 (LA) have been shown to protect against the development and progression of atherosclerosis in rabbits (Kritchevsky et al., 2002 and 2004), hamsters (Nicolosi et al., 1997; Wilson et al., 2000) and ApoE-KO mice (Toomey et al., 2003) when a pro-atherogenic diet was fed. Moreover, the addition of a cis-9, trans-11 CLA-rich mixture to butter depressed some risk factors of CVD in cholesterol-fed hamsters (Valeille et al., 2005).

Consequently, the enrichment of milk fat in cis-9, trans11 CLA could improve the nutritional value of milk fat. It is well established that the nutrition of cows is an efficient mean to modulate the FA composition of milk fat (Chilliard and Ferlay, 2004). Dietary strategies based on concentrate diets supplemented with oil rich in $C_{18: 2} n-6$ allow the marked increase in milk fat concentrations of both cis-9, trans-11 CLA and trans-11 C $18: 1$ (Bauman et al., 2000), the 
Roy, Chardigny, Bauchart, Ferlay, Lorenz, Durand, Gruffat, Faulconnier, Sébédio and Chilliard

latter being converted into the former in animal and human tissues (Santora et al., 2000; Turpeinen et al., 2002; Corl et al., 2003). Animal studies using a cis-9, trans-11 $\mathrm{CLA}+$ trans-11 $\mathrm{C}_{18: 1}$-enriched butter have been carried out, initially showing decreased chemically induced mammary tumours in rats (Ip et al., 1999), and improved plasma lipoprotein profile in cholesterol-fed hamsters, when compared with a standard butter (Lock et al., 2005). However, the cis- 9 , trans-11 CLA + trans-11 $\mathrm{C}_{18: 1}$-enriched butters used in the abovementioned studies contained non-negligible amounts of trans-10 $C_{18: 1}$ (ca. $2.8 \%$ of total $\mathrm{FA})$, a trans FA that is generally low in non-enriched milk fat $(<0.5 \%$ of total FA) and high in partially hydrogenated fats (Precht and Molkentin, 1996). However, trans-10 $C_{18: 1}$ is also increased under certain cow's feeding strategies (Chilliard and Ferlay, 2004). Very little is known about the effects of trans-10 $C_{18: 1}$ on cardiovascular parameters. Only one study reported a positive association between the concentration of trans-10 $C_{18: 1}$ in platelets and the degree of coronary artery disease in humans, while no association was reported for trans-11 $C_{18: 1}$ (Hodgson et al., 1996).

In order to explore the effects of the ingestion of trans$10 C_{18: 1}$ on several lipid parameters involved in atherosclerosis, butters either rich in trans-10 $\mathrm{C}_{18: 1}$ or trans-11 $\mathrm{C}_{18: 1}+$ cis-9, trans-11 CLA were included into an atherogenic diet offered to rabbits used as model of cholesterolinduced atherosclerosis. The experimental butters were compared with a standard butter (low in trans FA and rich in saturated FA), to evaluate their effects on aortic fatty streak observations, plasma FA and lipoprotein profiles, plasma eicosanoid concentrations, and the relationships between the aortic fatty streaks and plasma lipid parameters of rabbits.

\section{Material and methods}

Animals, diets and experimental design

Thirty-six male New Zealand White rabbits (age: $9.6 \pm 0.5$ weeks, body weight: $2.1 \pm 0.1 \mathrm{~kg}$, Les Dombes, Chatillon sur Chalaronne, France) were randomly divided into three groups of 12 animals on the age and body-weight basis. The animals were housed in individual stainless steel cages in a temperature-controlled room $\left(18^{\circ} \mathrm{C}\right)$ maintained on a 12-h light-dark cycle. The animals were allowed to free access to water and fed daily one of three diets containing $12 \%$ on a dry matter (DM) basis of butter, and supplemented with $0.2 \%$ DM of cholesterol. The three diets were prepared and pelleted by INRA (Institut National de la Recherche Agronomique, Station de Recherches Cunicoles, Toulouse, France), and contained ( $/ \mathrm{kg} D M)$ alfalfa flour (305), soya cake (233), butter (120), sucrose (102), beet pulp (100), barley (65), sunflower cake (50), maize oil (8), sodium chloride (5), calcium hydrogen phosphate (5), vitamin and mineral mix (5) and cholesterol (2). The DM concentration of these diets was $845 \mathrm{~g} / \mathrm{kg}$ feed and the composition was ( $/ \mathrm{kg} \mathrm{DM})$ : organic matter (921), crude cellulose (171), protein (nitrogen $\times 6.25$ ) (231), lipid (134),
FA (114). The three diets essentially differed in the FA composition of butters, i.e. a butter rich in trans-11 $\mathrm{C}_{18: 1}$ and cis-9, trans-11 CLA $(7.4 \%$ and $3.1 \%$ of total FA, respectively, T11-CLA diet), a butter rich in trans-10 $\mathrm{C}_{18: 1}(13.7 \%$ of total FA, T10 diet), or a butter with a standard FA composition $(1.2 \%, 0.4 \%$ and $0.3 \%$ of total FA as trans -11 $\mathrm{C}_{18: 1}$, cis-9, trans-11 CLA and trans-10 $\mathrm{C}_{18: 1}$, respectively, $\mathrm{S}$ diet), made from milk of cows fed different basal diets supplemented with plant oils (Roy et al., 2006). The FA composition of the three diets is presented in Table 1. The rabbits (T11-CLA, T10 and S groups) were fed the diets either for a 6 -week- (experiment $1, \mathrm{n}=6$ per diet) or a 12-week- (experiment 2, $\mathrm{n}=6$ per diet) experimental period. Food intake was measured daily, uneaten food was discarded once daily and body weight was recorded every week. All rabbits were killed at the end of the experiment after food deprivation for $17 \mathrm{~h}$.

\section{Blood sampling, plasma lipid and lipoprotein analyses}

At the end of the both experiment 1 and experiment 2, the rabbits were killed by cervical dislocation, and truncal blood samples $(50 \mathrm{ml})$ were collected into tubes containing $\mathrm{Na}_{2}-\mathrm{EDTA}, \mathrm{Na}-\mathrm{N}_{3}$ and merthiolate (final concentrations $3 \mathrm{mmol} / \mathrm{l}, 0.1$ and $0.01 \mathrm{~g} / \mathrm{l}$, respectively). Plasma was prepared by centrifugation of blood samples at $2700 \mathrm{~g}$ for

Table 1 Fatty acid composition (weight $\%$ of total fatty acids) of the three diets enriched with $12 \%$ of butter with either standard fatty acid composition (S diet), rich in trans-10 $C_{18: 1}$ (T10 diet) or rich in trans-11 $C_{18: 1}+$ cis-9, trans-11 CLA (T11-CLA diet)

\begin{tabular}{|c|c|c|c|}
\hline & \multicolumn{3}{|c|}{ Diet } \\
\hline & $\mathrm{S}$ & $\mathrm{T} 10$ & T11-CLA \\
\hline \multicolumn{4}{|l|}{ Fatty acids } \\
\hline$<\mathrm{C}_{12: 0}$ & 6.0 & 3.5 & 3.8 \\
\hline$C_{12: 0}$ & 3.8 & 2.1 & 2.0 \\
\hline $\mathrm{C}_{14: 0}$ & 10.7 & 7.8 & 6.8 \\
\hline$C_{16: 0}$ & 29.4 & 21.5 & 19.3 \\
\hline$C_{16: 1}$ & 1.7 & 2.0 & 1.4 \\
\hline$C_{18: 0}$ & 7.7 & 7.0 & 9.3 \\
\hline $\mathrm{C}_{18: 1}$ cis-9 & 16.6 & 16.8 & 20.9 \\
\hline $\mathrm{C}_{18: 1}$ cis-11 & 0.7 & 0.9 & 0.9 \\
\hline $\mathrm{C}_{18: 1}$ cis-12 & 0.2 & 0.3 & 0.6 \\
\hline $\mathrm{C}_{18: 1}$ cis-13 & 0.1 & 0.1 & 0.1 \\
\hline $\mathrm{C}_{18: 1}$ trans -9 & 0.3 & 0.6 & 0.9 \\
\hline $\mathrm{C}_{18: 1}$ trans- 10 & 0.4 & 11.8 & 2.2 \\
\hline $\mathrm{C}_{18: 1}$ trans-11 & 1.1 & 1.8 & 7.0 \\
\hline $\mathrm{C}_{18: 1}$ trans -13 & 0.4 & 0.5 & 0.8 \\
\hline$C_{18: 2} n-6$ & 9.8 & 10.1 & 11.0 \\
\hline CLA cis-9, trans-11 & 0.5 & 0.8 & 2.6 \\
\hline$C_{18: 3} n-3$ & 2.2 & 2.0 & 2.4 \\
\hline Others & 8.4 & 10.4 & 8.0 \\
\hline$\Sigma$ saturated fatty acids & 57.6 & 41.9 & 41.2 \\
\hline$\Sigma C_{18: 1}$ cis $^{\dagger}$ & 17.6 & 18.1 & 22.5 \\
\hline$\sum C_{18: 1}$ trans $^{\ddagger}$ & 2.2 & 14.7 & 10.9 \\
\hline
\end{tabular}

${ }^{\dagger}$ Sum of cis-9, cis-11, and cis-12 isomers.

${ }^{\ddagger}$ Sum of trans-6/7/8, trans-9, trans-10, trans-11, trans-12 and trans-15 isomers. 
$15 \mathrm{~min}$ at $15^{\circ} \mathrm{C}$. Three $500 \mu \mathrm{l}$ aliquots of plasma were stored at $-20^{\circ} \mathrm{C}$ until lipid and apolipoprotein analysis and one 20-ml fraction was treated immediately for lipoprotein fractionation. The isolation of lipoproteins for determination of the density distribution and chemical composition of lipoprotein subfractions was previously described (Bauchart et al., 1989). Briefly, plasma lipoproteins were separated by ultracentrifugation according to a three step-sequence, and chylomicrons were defined as lipoproteins of density $<0.950 \mathrm{~g} / \mathrm{ml}$, very low density lipoproteins (VLDL) as lipoproteins of density $=0.950$ to $1.018 \mathrm{~g} / \mathrm{ml}$, intermediary and low density lipoproteins (IDL and LDL) as lipoproteins of density $=1.018$ to $1.060 \mathrm{~g} / \mathrm{ml}$, and high density lipoproteins (HDL) as lipoproteins of density $=1.060$ to $1.180 \mathrm{~g} / \mathrm{ml}$. The non-HDL fraction corresponded to the sum of chylomicrons, VLDL and IDL + LDL subfractions. The enzymatic methods used for determination of lipid classes (free cholesterol, FC; total cholesterol, TC; triacylglycerols, TG; phospholipids, PL) in plasma and in lipoprotein subfractions have been described previously (Leplaix-Charlat et al., 1996). Cholesteryl esters (CE) content was calculated using the relationship: $\mathrm{CE}=(\mathrm{TC}-\mathrm{FC}) \times 1.68$. Plasma non-esterified FA (NEFA) concentration was determined spectrophotometrically by the acyl-CoA synthetase method (Wako-Unipath NEFA-C kit, Oxoid, Dardilly, France).

Blood samples were also collected in tubes containing either $\mathrm{Na}_{2}$-EDTA + indomethacin $(3 \mathrm{mmol} / \mathrm{l}$ and $40 \mathrm{mmol} / \mathrm{l}$, respectively) for estimation of prostacyclin (prostaglandin $\left.\mathrm{I}_{2}, \mathrm{PGI}_{2}\right)$ concentration, or indomethacin alone $(40 \mathrm{mmol} / \mathrm{l})$ for estimation of thromboxane $A_{2}\left(T_{x} A_{2}\right)$ concentration, or, when possible (i.e. when blood quantities were sufficient), $\mathrm{Na}_{2}$-EDTA alone $(3 \mathrm{mmol} / \mathrm{l})$ for determination of total FA composition in plasma.

\section{Eicosanoid and fatty acid analyses}

The blood samples for $\mathrm{PGI}_{2}$ assay were immediately centrifuged at $1000 \mathrm{~g}$ for $10 \mathrm{~min}$ at $4^{\circ} \mathrm{C}$, plasma was harvested and stored at $-80^{\circ} \mathrm{C}$ until analysis. The concentration of $\mathrm{PGI}_{2}$ was measured using an ELISA kit (intra- and interessay coefficients of variation $(\mathrm{CV})=2.9 \%$ and $6.0 \%$, respectively; DE 0800, R\&D Systems, Minneapolis, MN, USA) according to the manufacturer instructions. Briefly, concentration of $\mathrm{PGI}_{2}$ was monitored by measurement of 6-keto-prostaglandin $\mathrm{F}_{1 \alpha}$ (6-keto-PGF $\mathrm{P}_{1 \alpha}$ ) concentration, a stable metabolite produced by the non-enzymatic hydration of $\mathrm{PGl}_{2}$.

The blood samples for $\mathrm{TxA}_{2}$ assay were left for $2 \mathrm{~h}$ at room temperature, and serum was harvested after centrifugation (1000 $\mathrm{g}$ for $10 \mathrm{~min}$ at room temperature) according to the manufacturer instructions. The concentration of $\mathrm{TxA}_{2}$ was measured using an ELISA kit (intra- and inter-assay $\mathrm{CV}=1.6 \%$ and $6.2 \%$, respectively; $\mathrm{DE} 0700, \mathrm{R} \& \mathrm{D}$ Systems, Minneapolis, MN, USA). The concentration of $\mathrm{TxA}_{2}$ was monitored by measurement of $\mathrm{TXB}_{2}$ concentration, a stable metabolite produced by the non-enzymatic hydration of $\mathrm{TxA}_{2}$.
For determination of plasma FA composition, the blood samples were immediately centrifuged $(2700 \mathrm{~g}$ for $15 \mathrm{~min}$ at $15^{\circ} \mathrm{C}$ ), and plasma (ca. $1 \mathrm{ml}$ ) was stored in $2 \mathrm{ml}$ of chloroform/methanol $(2: 1, \mathrm{v} / \mathrm{v})$ at $-80^{\circ} \mathrm{C}$ until $\mathrm{FA}$ analysis. Plasma FA were extracted and trans-methylated according to the procedure of Christie et al. (2001), and the FA methyl esters (FAME) were stored at $-20^{\circ} \mathrm{C}$ until analysis. The FAME were separated using a gas chromatograph (Hewlett Packard Model 4890, Palo Alto, CA, USA) equipped with a flame-ionisation detector, automatic injector, split injection port and a $100 \mathrm{~m}$ fused capillary column $(100 \mathrm{~m} \times 0.2 \mathrm{~mm}$ i.d., $0.2 \mu \mathrm{m}$ film, CP-Sil 88, Varian, Courtaboeuf, France) using hydrogen as the carrier gas $(35 \mathrm{ml} /$ min). Injector and detector temperatures were maintained at $250^{\circ} \mathrm{C}$. Total FAME profile was determined using a temperature gradient program. Following sample injection, column temperature was maintained at $60^{\circ} \mathrm{C}$ for $1 \mathrm{~min}$, increased at a rate of $3^{\circ} \mathrm{C} / \mathrm{min}$ to $85^{\circ} \mathrm{C}$, raised to $190^{\circ} \mathrm{C}$ at a rate of $20^{\circ} \mathrm{C} / \mathrm{min}$, held at $190^{\circ} \mathrm{C}$ for $70 \mathrm{~min}$, increased at $20^{\circ} \mathrm{C} / \mathrm{min}$ to a final temperature of $210^{\circ} \mathrm{C}$ that was maintained for $5 \mathrm{~min}$. More detailed analysis of the distribution of individual isomers of $\mathrm{C}_{18: 1}$ was determined using a $120 \mathrm{~m}$ fused capillary column $(120 \mathrm{~m} \times 0.25 \mathrm{~mm}$ i.d., $0.25 \mu \mathrm{m}$ film, BPX70, SGE, Melbourne, Australia) with hydrogen as the carrier gas $(35 \mathrm{ml} / \mathrm{min})$. Injector and detector temperatures were maintained at $250^{\circ} \mathrm{C} . \mathrm{C}_{18: 1}$ FAME profile was determined using a temperature gradient program. Following sample injection, column temperature was maintained at $60^{\circ} \mathrm{C}$ for $1 \mathrm{~min}$, increased at a rate of $20^{\circ} \mathrm{Cl}$ min to $160^{\circ} \mathrm{C}$, held at $160^{\circ} \mathrm{C}$ for $40 \mathrm{~min}$, increased at a rate of $20^{\circ} \mathrm{C} / \mathrm{min}$ to a final temperature of $220^{\circ} \mathrm{C}$ that was maintained for $20 \mathrm{~min}$.

Total lipids in diets were extracted according to the method of Folch et al. (1957) and saponified overnight in an ethanolic potassium hydroxide solution $(100 \mathrm{~g} / \mathrm{l})$. The FA were methylated at room temperature by the $\mathrm{BF}_{3} / \mathrm{Na}$ methanolate method (Sebedio et al., 1999), and subsequently analyzed by gas-liquid chromatography using a DI 200 chromatograph (Perichrom, Saulx-les-Chartreux, France) equipped with a CP-Sil 88 fused-silica capillary column (length $100 \mathrm{~m}$, i.d. $0.25 \mathrm{~mm}$ ). The carrier gas was hydrogen $(1.1 \mathrm{ml} / \mathrm{min})$ in conditions of split injection (1/50). Injector and detector temperatures were $235^{\circ} \mathrm{C}$ and $250^{\circ} \mathrm{C}$, respectively. The oven temperature was held constant for $30 \mathrm{~s}$ at $70^{\circ} \mathrm{C}$, then increased from $70^{\circ} \mathrm{C}$ to $175^{\circ} \mathrm{C}$ at $20^{\circ} \mathrm{C} / \mathrm{min}$, held at $175^{\circ} \mathrm{C}$ for $25 \mathrm{~min}$, increased again from 175 to $215^{\circ} \mathrm{C}$ at $10^{\circ} \mathrm{C} / \mathrm{min}$, and was finally held at $215^{\circ} \mathrm{C}$ for $41 \mathrm{~min}$.

\section{Liver lipids}

Total lipids in the liver were determined gravimetrically after their extraction by mixing $5 \mathrm{~g}$ of fresh tissue with chloroform/methanol 2:1 (v/v) according to the method of Folch et al. (1957). The PL content was determined from total lipid extract by colorimetry after mineralization of organic phosphorus according to the method of Bartlett (1959). The TG content was analysed from total lipids according to the following method: after elimination of PL 
absorbed on silicic acid, TG were saponified by $4 \mathrm{~mol} / \mathrm{l}$ $\mathrm{KOH}$-ethanol, followed by neutralisation with $4 \mathrm{~mol} / \mathrm{l} \mathrm{HCl}$ and centrifugation. The free glycerol that was released in the supernatant was enzymatically determined using a TG test kit (PAP 1000; Biomérieux, France). The TC content was enzymatically measured from total lipid extract using a reagent kit (CHOD-iodide; Merck, Darmstadt, Germany).

\section{Fatty streak areas}

At the end of experiment 2, and after blood collection, aortas were fixed according to the method of Wilson et al. (2000) with modifications: a perfusion needle was inserted into the left ventricle and $100 \mathrm{ml}$ of a $10 \%$ buffered formalin solution (HT50-1-128, Sigma-Aldrich, Saint-Quentin Fallavier, France) was slowly perfused. The aortas were cut abdominally to provide an outlet for the fixative. After perfusion, the heart and thoracic aorta were removed and fixation completed by leaving ca. $24 \mathrm{~h}$ in the fixative at $4^{\circ} \mathrm{C}$. The tissues were then rinsed with PBS at $4^{\circ} \mathrm{C}$ and stored at $4^{\circ} \mathrm{C}$ in vials containing PBS for subsequent analysis of fatty streak area. Then, the aorta was carefully isolated from the heart to keep the arch intact, longitudinally opened and placed in a solution of $0.5 \mathrm{~g}$ Oil Red 0 (0-062, SigmaAldrich, Saint-Quentin Fallavier, France) in $100 \mathrm{ml}$ of $70 \%$ isopropanol for $25 \mathrm{~min}$. Subsequently, aorta was rinsed in $70 \%$ isopropanol for $4 \mathrm{~min}$ and finally in distilled water for $3 \mathrm{~min}$. Aortas were then included in a mounting media with the endothelial side up, and the areas of lipid deposition in the endothelium (coloured in strong red) were graded visually using a 0 to 3 scale ( 0 corresponded to the absence of lipid deposition and 3 to maximal lipid deposition) by four independent observers. The lipid infiltration was easily evaluated, due to the large size of the fatty streaks and the well-responsiveness of the rabbit aorta, thus limiting the coloration artefacts, as shown in Figure 1.

\section{Statistical analysis}

Data were analysed using the two-way ANOVA procedure of Statistical Analysis Systems Institute (SAS; 1985) to determine the effects of the diet $(D)$, the experiment $(E$, experiment $1 \mathrm{v}$. experiment 2) and their interaction $(D \times E)$, and are expressed as mean \pm pooled standard error of the mean. When the $D$ and/or $E$ effects were significant $(P<0.05)$, the differences between the six groups were tested using the PLSD Fisher test (Tables 2 and 4). When the $D$ effect was significant $(P<0.05)$, data were analysed also with the one-way ANOVA procedure of SAS (1985), and the differences between the three diets (as indicated in the Results section) were tested using the PLSD Fisher test. The frequencies of infiltrated aortas per group presented in Table 3 were analysed using the chi-squared test. The D and $E$ effects were declared significant at $P<0.05$, and their interaction at $P<0.10$.

\section{Results}

The three experimental diets were well accepted by the rabbits, except for two rabbits fed the T10 diet.

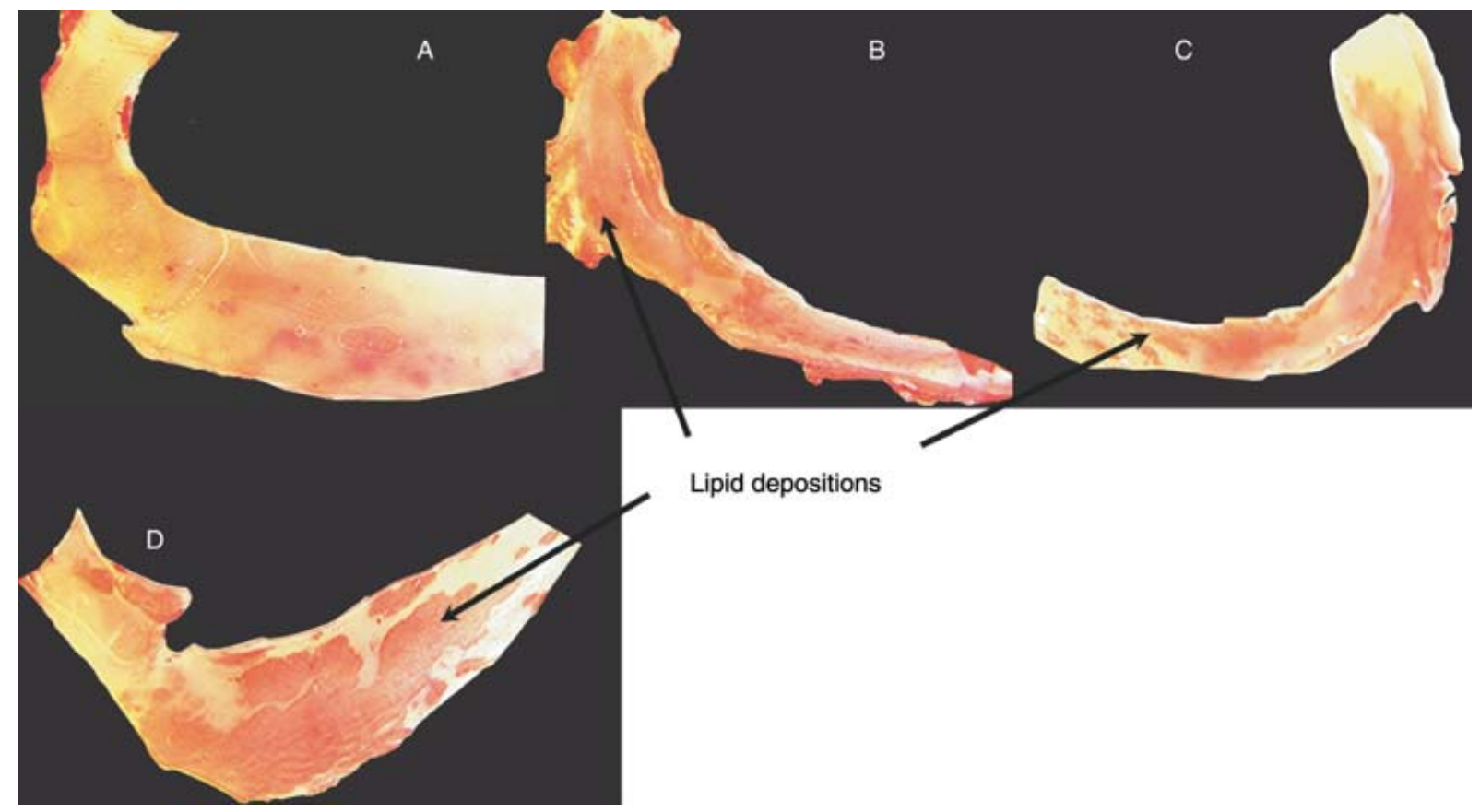

Figure 1 Aorta fatty streak scoring in the New Zealand White rabbits fed a diet supplemented with $0.2 \%$ (dry matter, DM) cholesterol and containing $12 \%$ (DM) butter. Aortas were fixed with 10\% buffered formalin solution and lipid depositions were stained with a solution of Oil Red 0 in isopropanol. The note 0 corresponded to the absence of fatty streak (A), the notes 1 or 2 corresponded to mild fatty streak (B and C, respectively), and the note 3 corresponded to strong lipid infiltration (D). 
trans fatty acid-rich butters and atherosclerosis

Table 2 Effects of an atherogenic diet containing 12\% (dry matter) of a standard butter (S diet), or butter either rich in trans-10 $C_{18: 1}$ (T10 diet) or trans-11 $C_{18: 1}+$ cis-9, trans-11 CLA (T11-CLA diet) for 6 weeks (experiment 1) or 12 weeks (experiment 2) on plasma fatty acid composition (\% of total fatty acids)

\begin{tabular}{|c|c|c|c|c|c|c|c|c|c|c|}
\hline \multirow[b]{2}{*}{ Diets } & \multicolumn{3}{|c|}{ Experiment 1} & \multicolumn{3}{|c|}{ Experiment 2} & \multirow[b]{2}{*}{ s.e. } & \multicolumn{3}{|c|}{$P$ value $^{\dagger}$} \\
\hline & $\mathrm{s}$ & T10 & T11-CLA & $s$ & T10 & T11-CLA & & D & $\mathrm{E}$ & $D \times E$ \\
\hline No. & 4 & 4 & 4 & 5 & 6 & 5 & & & & \\
\hline \multicolumn{11}{|l|}{ Fatty acids } \\
\hline$C_{14: 0}$ & $0.26^{d}$ & $0.28^{\mathrm{d}}$ & $0.22^{c}$ & $0.14^{\mathrm{a}}$ & $0.14^{\mathrm{a}}$ & $0.17^{b}$ & 0.01 & 0.49 & 0.01 & 0.01 \\
\hline$C_{15: 0}$ & $0.41^{\mathrm{c}}$ & $0.41^{c}$ & $0.42^{c}$ & $0.21^{\mathrm{a}}$ & $0.28^{\mathrm{b}}$ & $0.27^{\mathrm{b}}$ & 0.02 & 0.21 & 0.01 & 0.28 \\
\hline$C_{16: 0}$ & $22.41^{\mathrm{c}}$ & $20.70^{b c}$ & $20.69^{b c}$ & $19.41^{\mathrm{ab}}$ & $18.68^{\mathrm{a}}$ & $18.55^{\mathrm{a}}$ & 0.61 & 0.13 & 0.01 & 0.74 \\
\hline$C_{16: 1} n-9$ & $0.32^{\mathrm{b}}$ & $0.40^{c}$ & $0.32^{\mathrm{b}}$ & $0.23^{\mathrm{a}}$ & $0.25^{\mathrm{a}}$ & $0.28^{\mathrm{ab}}$ & 0.02 & 0.13 & 0.01 & 0.11 \\
\hline$C_{17: 0}$ & $0.66^{\mathrm{bc}}$ & $0.67^{c}$ & $0.62^{\mathrm{bc}}$ & $0.47^{\mathrm{a}}$ & $0.63^{\mathrm{b}}$ & $0.56^{\mathrm{ab}}$ & 0.04 & 0.09 & 0.01 & 0.14 \\
\hline$C_{18: 0}$ & $17.99^{\mathrm{a}}$ & $17.93^{\mathrm{a}}$ & $17.95^{\mathrm{a}}$ & $19.71^{b}$ & $19.77^{b}$ & $18.80^{\mathrm{ab}}$ & 0.41 & 0.27 & 0.01 & 0.70 \\
\hline$C_{18: 1}$ cis- 9 & $12.97^{\mathrm{ab}}$ & $12.96^{\mathrm{ab}}$ & $13.93^{\mathrm{b}}$ & $13.57^{b}$ & $12.18^{\mathrm{a}}$ & $13.76^{\mathrm{b}}$ & 0.43 & 0.04 & 0.75 & 0.35 \\
\hline$C_{18: 1}$ cis-11 & $0.96^{\mathrm{a}}$ & $1.41^{\mathrm{bc}}$ & $1.16^{\mathrm{ab}}$ & $1.59^{c}$ & $1.29^{b}$ & $1.33^{\mathrm{bc}}$ & 0.11 & 0.60 & 0.02 & 0.01 \\
\hline$C_{18: 1}$ cis-12 & $0.23^{\mathrm{a}}$ & $0.19^{\mathrm{a}}$ & $0.49^{b}$ & $0.24^{\mathrm{a}}$ & $0.30^{\mathrm{a}}$ & $0.48^{\mathrm{b}}$ & 0.05 & 0.01 & 0.40 & 0.44 \\
\hline $\mathrm{C}_{18: 1}$ trans- $6 / 7 / 8$ & 0.03 & 0.10 & 0.09 & 0.04 & 0.26 & 0.11 & 0.07 & 0.21 & 0.35 & 0.59 \\
\hline $\mathrm{C}_{18: 1}$ trans- 9 & $0.27^{\mathrm{a}}$ & $0.57^{\mathrm{b}}$ & $0.57^{\mathrm{b}}$ & $0.34^{\mathrm{a}}$ & $0.62^{\mathrm{b}}$ & $0.69^{b}$ & 0.05 & 0.01 & 0.07 & 0.78 \\
\hline$C_{18: 1}$ trans -10 & $0.07^{\mathrm{a}}$ & $1.58^{\mathrm{d}}$ & $0.31^{\mathrm{b}}$ & $0.06^{\mathrm{a}}$ & $1.30^{c}$ & $0.35^{\mathrm{b}}$ & 0.06 & 0.01 & 0.12 & 0.03 \\
\hline$C_{18: 1}$ trans-11 & $0.43^{\mathrm{ab}}$ & $0.47^{\mathrm{ab}}$ & $1.37^{c}$ & $0.34^{\mathrm{a}}$ & $0.56^{\mathrm{b}}$ & $1.50^{c}$ & 0.07 & 0.01 & 0.44 & 0.27 \\
\hline$C_{18: 1}$ trans -12 & $0.26^{\mathrm{a}}$ & $0.35^{\mathrm{a}}$ & $0.55^{b c}$ & $0.27^{\mathrm{a}}$ & $0.46^{\mathrm{b}}$ & $0.64^{c}$ & 0.03 & 0.01 & 0.01 & 0.34 \\
\hline$C_{18: 1}$ trans-15 & $0.10^{\mathrm{ab}}$ & $0.07^{\mathrm{a}}$ & $0.14^{\mathrm{bc}}$ & $0.10^{\mathrm{ab}}$ & $0.11^{\mathrm{ab}}$ & $0.18^{\mathrm{c}}$ & 0.02 & 0.01 & 0.03 & 0.47 \\
\hline$C_{18: 2} n-6$ & $32.00^{\mathrm{bc}}$ & $31.82^{b c}$ & $30.32^{\mathrm{a}}$ & $32.37^{b c}$ & $32.54^{c}$ & $31.59^{b}$ & 0.34 & 0.01 & 0.01 & 0.46 \\
\hline CLA cis-9, trans-11 & $0.20^{\mathrm{a}}$ & $0.20^{\mathrm{a}}$ & $0.83^{\mathrm{b}}$ & $0.20^{\mathrm{a}}$ & $0.24^{\mathrm{a}}$ & $1.01^{\mathrm{b}}$ & 0.06 & 0.01 & 0.17 & 0.38 \\
\hline$C_{18: 3} n-3$ & $1.03^{\mathrm{e}}$ & $0.97^{\text {cde }}$ & $0.85^{\mathrm{bc}}$ & $1.00^{\mathrm{de}}$ & $0.67^{\mathrm{a}}$ & $0.77^{\mathrm{ab}}$ & 0.05 & 0.01 & 0.01 & 0.03 \\
\hline$C_{20: 4} n-6$ & $5.64^{\mathrm{b}}$ & $4.70^{\mathrm{a}}$ & $5.33^{\mathrm{ab}}$ & $6.07^{\mathrm{b}}$ & $5.65^{b}$ & $5.32^{\mathrm{ab}}$ & 0.26 & 0.05 & 0.05 & 0.23 \\
\hline$C_{20: 5} n-3$ & $0.18^{\mathrm{c}}$ & $0.07^{\mathrm{a}}$ & $0.10^{\mathrm{ab}}$ & $0.16^{\mathrm{bc}}$ & $0.15^{\mathrm{bc}}$ & $0.13^{\mathrm{abc}}$ & 0.02 & 0.02 & 0.15 & 0.13 \\
\hline$C_{22: 6} n-3$ & $0.11^{c}$ & $0.04^{\mathrm{a}}$ & $0.07^{\mathrm{ab}}$ & $0.12^{c}$ & $0.08^{\mathrm{abc}}$ & $0.09^{a b c}$ & 0.02 & 0.02 & 0.10 & 0.79 \\
\hline$\sum$ saturated fatty acids ${ }^{\ddagger}$ & 41.80 & 40.14 & 39.64 & 40.00 & 39.55 & 38.39 & 0.70 & 0.08 & 0.07 & 0.74 \\
\hline$\sum C_{18: 1} c i s^{\S}$ & $14.16^{\mathrm{ab}}$ & $14.56^{\mathrm{ab}}$ & $15.59^{b}$ & $15.40^{\mathrm{b}}$ & $13.77^{\mathrm{a}}$ & $15.57^{b}$ & 0.47 & 0.03 & 0.73 & 0.15 \\
\hline$\Sigma C_{18: 1}$ trans" & $1.14^{\mathrm{a}}$ & $3.13^{\mathrm{b}}$ & $3.02^{b}$ & $1.15^{\mathrm{a}}$ & $3.21^{\mathrm{b}}$ & $3.47^{\mathrm{b}}$ & 0.18 & 0.01 & 0.27 & 0.48 \\
\hline$\sum$ n-6 fatty acids & $39.26^{\mathrm{bc}}$ & $38.10^{\mathrm{ab}}$ & $37.32^{\mathrm{a}}$ & $40.31^{c}$ & $39.82^{c}$ & $38.74^{\mathrm{b}}$ & 0.38 & 0.01 & 0.01 & 0.71 \\
\hline$\Sigma$ n-3 fatty acids & $1.71^{\mathrm{b}}$ & $1.31^{\mathrm{a}}$ & $1.36^{\mathrm{a}}$ & $1.67^{\mathrm{b}}$ & $1.28^{\mathrm{a}}$ & $1.27^{\mathrm{a}}$ & 0.07 & 0.01 & 0.34 & 0.88 \\
\hline n-6/n-3 ratio & $23.28^{\mathrm{a}}$ & $29.41^{c d}$ & $27.61^{b c}$ & $24.35^{\mathrm{ab}}$ & $31.18^{d}$ & $30.63^{\mathrm{cd}}$ & 1.18 & 0.01 & 0.05 & 0.71 \\
\hline
\end{tabular}

$a, b, c$ Mean values within a row with different superscripts are significantly different $(P<0.05)$

${ }^{\dagger} P$ values for the diet effect $(D)$, experiment effect $(E)$ and their interaction $(D \times E)$. When the diet and/or experiment effects are significant $(P<0.05)$.

${ }^{\ddagger}$ Sum of $C_{14: 0}, C_{15: 0}, C_{16: 0}, C_{17: 0}, C_{18: 0}$ and $C_{20: 0}$.

${ }^{\S}$ Sum of cis-9, cis-11, and cis-12 isomers.

"Sum of trans-6/7/8, trans-9, trans-10, trans-11, trans-12 and trans-15 isomers.

The food intakes have been reported elsewhere (Faulconnier et al., 2006).

\section{Plasma fatty acid composition}

The proportion of total saturated FA in rabbit plasma tended to be affected by the diet $(P<0.08)$ and the duration of feeding diets (experiment effect, $P<0.07$ ) (Table 2). The proportions of $C_{14: 0}, C_{15: 0}, C_{16: 0}$ and $C_{17: 0}$ were decreased between experiment 1 and experiment 2 with the three diets, while that of $C_{18: 0}$ was increased between experiment 1 and experiment 2 with the $S$ and T10 diets.

The effect of the diet was significant $(P<0.03$, $\mathrm{T} 10<\mathrm{T} 11-\mathrm{CLA}$ diet) on the proportions of plasma total cis$\mathrm{C}_{18: 1}$. The proportion of total trans- $\mathrm{C}_{18: 1}$ was higher in plasma from rabbits fed the T10 and T11-CLA diets than in rabbits fed the $S$ diet in the two experiments $(P<0.05)$. Particularly, the diets rich in trans FA resulted in higher plasma proportion of trans-9 $C_{18: 1}$ in the two experiments, the T11-CLA diet increased those of trans-11, trans-12 and trans-15 $C_{18: 1}$ and the T10 diet increased that of trans-10 $C_{18: 1}$ in both experiments, compared with the $S$ diet $(P<0.05)$.

Conversely, n-3 FA proportions were decreased, and the $n-6$ to $n-3$ ratio was increased, in plasma from rabbits of T10 and T11-CLA groups compared with the $S$ group $(P<0.05)$, and the $C_{18: 3} n-3$ proportion was particularly decreased in plasma from rabbits fed either the T10 or the T11-CLA diets (significant $D \times E$ interaction, $P<0.01$ ). The content of cis-9, trans-11 CLA in plasma was increased by four-fold with the T11-CLA diet, compared with the two other diets in the two experiments $(P<0.05)$. The diet effect was significant for the plasma proportions of n-6 FA $(P<0,01, \mathrm{~T} 11-\mathrm{CLA}<\mathrm{T} 10$ and $\mathrm{S}$ diets $)$.

Fatty streak areas and plasma concentrations of eicosanoids The proportion of rabbits showing lipid infiltration in the aorta was significantly higher in the T10 diet than in the 
Roy, Chardigny, Bauchart, Ferlay, Lorenz, Durand, Gruffat, Faulconnier, Sébédio and Chilliard

Table 3 Effects of an atherogenic diet containing 12\% of a standard butter ( $S$ diet, $n=6)$, or butter either rich in trans-10 $C_{18: 1}$ ( $(T 10$ diet, $n=5)$ or trans-11 $C_{18: 1}+$ cis-9, trans-11 CLA (T11-CLA diet, $n=6)$ for 12 weeks (experiment 2) on lipid infiltration in aorta wall of the rabbits

\begin{tabular}{|c|c|c|c|c|}
\hline & \multicolumn{3}{|c|}{$\begin{array}{c}\text { Severity } \\
\text { of infiltration }\end{array}$} & \multirow{2}{*}{$\begin{array}{l}\text { Infiltration } \\
\text { occurrence }\end{array}$} \\
\hline & 0 & + & ++ & \\
\hline \multicolumn{5}{|l|}{ Diets } \\
\hline$S$ & 1 & 2 & 3 & $5 / 6^{a b}$ \\
\hline $\mathrm{T} 10$ & 0 & 4 & 1 & $5 / 5^{b}$ \\
\hline T11-CLA & 4 & 0 & 2 & $2 / 6^{a}$ \\
\hline
\end{tabular}

${ }^{a, b}$ Ratios with unlike superscript letters are significantly different between diets $(P<0.05)$.

${ }^{\dagger}$ Values are presented as the number of rabbits showing no fatty streak (0), mild fatty streak $(+$, mean score between 0.25 and 1.5$)$ or severe fatty streak $(++$, mean score between 1.5 and 3$)$ areas in aorta wall.

${ }^{\ddagger}$ Number of rabbits showing a lipid infiltration in aorta wall/total number of rabbits.

T11-CLA diet $(P<0.05$, Table 3$)$. The proportion of rabbits showing aortic lipid infiltration was lower in the T11-CLA group than in the $S$ group, although this difference was not significant.

Feeding butters of standard FA composition or rich in either trans-10 $C_{18: 1}$ or trans-11 $C_{18: 1}+$ cis-9, trans-11
CLA included into a pro-atherogenic diet for 6 or 12 weeks did not result in significant differences in the plasma concentrations of $\mathrm{PGI}_{2}$ and $\mathrm{TxA}_{2}$ (Table 4).

Plasma lipid and lipoprotein concentration and composition The cholesterolemia tended to be modified by the diet $(P<0.09$, T10 $>$ T11-CLA diet) (Table 4).The plasma cholesterol concentration in the VLDL fraction (VLDL-C) was significantly changed by the dietary treatment $(P<0.04, \mathrm{~T} 10>\mathrm{T} 11-\mathrm{CLA}$ and $\mathrm{S}$ diets). The plasma concentration of cholesterol in the LDL fraction (LDL-C) tended to be dependent on the dietary treatment $(P<0.07$, T10 $>$ T11-CLA diet, $S$ diet being intermediate). The plasma concentration of cholesterol in the HDL fraction (HDL-C) tended to be differently affected by the dietary treatments $(P<0.06, \mathrm{~T} 11-\mathrm{CLA}<\mathrm{S}$ and T10 diets) and was significantly decreased between experiment 1 and experiment $2(P<0.02)$, particularly in the T10 group $(P<0.05)$.

The triglyceridemia was differently affected by the duration of feeding the diets $(D \times E$ interaction, $P<0.08)$. Indeed, only the $S$ diet increased the triglyceridemia between experiment 1 and experiment 2 $(P<0.05)$, and the triglyceridemia was significantly lower with the T10 diet than with the $S$ diet in experiment $2(P<0.05)$.

Table 4 Effects of an atherogenic diet containing 12\% (dry matter) of a standard butter (S diet), or butter either rich in trans-10 $C_{18: 1}$ (T10 diet) or trans-11 C $18: 1+$ cis-9, trans-11 CLA (T11-CLA diet), for 6 weeks (experiment 1) or 12 weeks (experiment 2) on liver and plasma lipid concentrations, plasma lipoprotein and eicosanoid concentrations

\begin{tabular}{|c|c|c|c|c|c|c|c|c|c|c|}
\hline \multirow[b]{2}{*}{ Diets } & \multicolumn{3}{|c|}{ Experiment 1} & \multicolumn{3}{|c|}{ Experiment 2} & \multirow[b]{2}{*}{ s.e. } & \multicolumn{3}{|c|}{$P$ value $^{\dagger}$} \\
\hline & $\mathrm{S}$ & T10 & T11-CLA & $\mathrm{S}$ & $\mathrm{T} 10$ & T11-CLA & & $\mathrm{D}$ & $E$ & $D \times E$ \\
\hline No. & 5 & 6 & 6 & 6 & 6 & 6 & & & & \\
\hline \multicolumn{11}{|l|}{ Liver lipids (mg/g liver) } \\
\hline Total lipids & 61.0 & 57.9 & 60.0 & 70.1 & 76.1 & 80.7 & 8.42 & 0.85 & 0.03 & 0.78 \\
\hline Total cholesterol & 9.41 & 12.2 & 11.8 & 13.8 & 15.6 & 13.7 & 4.02 & 0.86 & 0.34 & 0.96 \\
\hline Triacylglycerols & $6.94^{\mathrm{ab}}$ & $3.77^{\mathrm{a}}$ & $4.78^{\mathrm{ab}}$ & $9.06^{b}$ & $8.88^{b}$ & $14.7^{c}$ & 1.78 & 0.18 & 0.01 & 0.11 \\
\hline \multicolumn{11}{|l|}{ Plasma lipids (mg/dl) } \\
\hline Total cholesterol (TC) & 198 & 475 & 271 & 291 & 384 & 173 & 99.1 & 0.09 & 0.70 & 0.57 \\
\hline VLDL-C & $58.2^{\mathrm{a}}$ & $245^{b}$ & $113^{a b}$ & $119^{\mathrm{ab}}$ & $208^{\mathrm{ab}}$ & $72.7^{\mathrm{a}}$ & 59.1 & 0.04 & 0.92 & 0.64 \\
\hline LDL-C ${ }^{\ddagger}$ & 101 & 207 & 110 & 76.3 & 144 & 50.8 & 43.4 & 0.07 & 0.18 & 0.89 \\
\hline $\mathrm{HDL}-\mathrm{C}$ & $26.6^{\mathrm{b}}$ & $29.2^{b}$ & $18.1^{\mathrm{a}}$ & $20.5^{\mathrm{ab}}$ & $17.5^{\mathrm{a}}$ & $11.8^{\mathrm{a}}$ & 3.90 & 0.06 & 0.02 & 0.71 \\
\hline LDL-C/HDL-C ratio ${ }^{\S}$ & 3.35 & 7.25 & 6.79 & 3.26 & 6.28 & 4.54 & 1.75 & 0.16 & 0.45 & 0.83 \\
\hline TC/HDL-C ratio" & 7.03 & 17.0 & 16.1 & 12.5 & 19.6 & 20.0 & 5.43 & 0.24 & 0.39 & 0.97 \\
\hline Triacylglycerols (TG) & $76.0^{\mathrm{a}}$ & $164^{\mathrm{ab}}$ & $103^{b}$ & $270^{\mathrm{b}}$ & $112^{\mathrm{a}}$ & $166^{\mathrm{ab}}$ & 50.6 & 0.72 & 0.12 & 0.08 \\
\hline \multicolumn{11}{|c|}{ Plasma lipoproteins (mg/dl) } \\
\hline Non-HDL & $432^{\mathrm{ab}}$ & $1,096^{b}$ & $556^{\mathrm{ab}}$ & $565^{\mathrm{ab}}$ & $905^{\mathrm{ab}}$ & $349^{a}$ & 238 & 0.05 & 0.66 & 0.74 \\
\hline $\mathrm{HDL}$ & $182^{\mathrm{b}}$ & $175^{\mathrm{b}}$ & $127^{\mathrm{a}}$ & $177^{\mathrm{b}}$ & $153^{\mathrm{ab}}$ & $138^{\mathrm{ab}}$ & 16.1 & 0.02 & 0.70 & 0.59 \\
\hline Non-HDL/HDL ratio & 2.32 & 6.60 & 4.65 & 3.00 & 5.95 & 2.64 & 1.55 & 0.08 & 0.61 & 0.70 \\
\hline \multicolumn{11}{|c|}{ Plasma eicosanoids (pg/ml) } \\
\hline $\mathrm{PGI}_{2}$ & 3161 & 5466 & 3803 & 4703 & 5530 & 4562 & 905 & 0.18 & 0.28 & 0.71 \\
\hline $\mathrm{TxA}_{2}$ & 42200 & 44409 & 42011 & 42248 & 42820 & 40525 & 1319 & 0.22 & 0.36 & 0.78 \\
\hline
\end{tabular}

a,b,c Mean values within a row with different superscripts are significantly different $(P<0.05)$.

${ }^{\dagger} P$ values for the diet effect $(D)$, experiment effect $(E)$ and their interaction $(D \times E)$. When the diet and/or experiment effects are significant $(P<0.05)$.

${ }_{5}^{\ddagger} \mathrm{LDL}$ fraction included IDL + LDL particles.

$\S$ The ratio was calculated as cholesterol content of IDL + LDL particles / cholesterol content of HDL fraction.

"The ratio was calculated as plasma total cholesterol / total cholesterol content of HDL fraction.

"Non-HDL fraction included chylomicrons, VLDL, IDL and LDL particles. 
The plasma concentrations of the HDL fraction were dependent on diet $(P<0.02, \mathrm{~T} 11-\mathrm{CLA}<\mathrm{S}$ diet, T10 diet being intermediate). The plasma concentrations of non-HDL fraction (including chylomicrons, VLDL, IDL and LDL) were also modified by the dietary treatment $(P<0.05, \mathrm{~T} 10>\mathrm{S}$ and T11-CLA diets). Moreover, non-HDL to HDL ratio tended to be affected by diet $(P<0.1, T 10>S$ diet, T11CLA diet being intermediate).

The severity of FA streak infiltration in aorta at 12 weeks (experiment 2) was positively and curvilinearly correlated with cholesterolemia, triglyceridemia, TC to HDL-C and non-HDL-C to HDL-C ratios (Table 5).

\section{Liver lipids}

While no difference was observed among the diets and between the experiments in the total lipid and TC contents of the liver, the T11-CLA diet slightly, but significantly increased $(P<0.05)$ the TG content of the liver in experiment 2 compared with the two other diets (Table 4). The T10 and T11-CLA diets resulted in a significant increase $(P<0.05)$ in the TG content of the liver between experiment 1 and experiment 2.

When compiling the data from the three diets in experiment 2, positive curvilinear correlations were observed between the severity of FA streak infiltration in aorta and the liver lipid or total cholesterol content (Table 5).

\section{Discussion}

While the food intake was similar for all rabbits receiving the $S$ and T11-CLA butters, two rabbits of the group receiving the T10 butter showed significant food refusals during the last week of experiment 2 (Faulconnier et al., 2006). These two rabbits also showed largely elevated cholesterolemia and non-HDL concentrations, a fatty liver and lipid infiltrations in the aorta wall. Thus, both the relatively limited number of rabbits per group and the great individual

Table 5 Relationships ( $\mathrm{P}<0.05, n=17$ ) between the severity of fatty streak areas in the aorta wall $(Y)$ and selected plasma and liver lipid parameters $(X)$ of the rabbits fed an atherogenic diet containing $12 \%$ (dry matter) of a standard butter (S diet), or butter either rich in trans-10 $C_{18: 1}$ (T10 diet) or trans-11 $C_{18: 1}+$ cis-9, trans-11 CLA (T11-CLA diet), for 12 weeks (experiment 2)

\begin{tabular}{llc}
\hline \hline & \multicolumn{2}{c}{ Relationship } \\
\cline { 2 - 3 } Lipid parameters & \multicolumn{1}{c}{ Equation } & $r$ \\
\hline Cholesterolemia & $Y=0.691 \cdot \ln (X)-2.395$ & 0.71 \\
Triglyceridemia & $Y=1.207 \cdot \ln (X)-4.791$ & 0.87 \\
TC / HDL-C & $Y=0.914 \cdot \ln (X)-1.196$ & 0.69 \\
Non-HDL-C / HDL-C & $Y=0.712 \cdot \ln (X)-0.373$ & 0.72 \\
Liver total lipid content & $Y=2.884 \cdot \ln (X)-11.250$ & 0.75 \\
Liver total cholesterol content & $Y=-0.003 X^{2}+0.194 X-0.697$ & 0.85 \\
\hline \hline
\end{tabular}

${ }^{\dagger}$ Plasma total cholesterol to HDL-cholesterol ratio.

${ }^{\ddagger}$ Plasma non-HDL-cholesterol to HDL-cholesterol ratio. variability within groups, especially in the T10 group, could explain at least in part the fact that differences in several parameters among the three groups were not significant. Consequently, this justifies caution in interpreting and discussing the results.

The trans-10 and trans-11 $\mathrm{C}_{18: 1}$ and cis-9, trans-11 CLA contents of the rabbit plasmas well reflected the type of ingested butter, being already significant after 6 weeks of feeding the enriched butters. Moreover, intake of trans FArich butters lowered the plasma content of total n-3 FA and particularly $C_{18: 3} n-3$, despite the fact that all diets provided the same amounts of $C_{18: 3} n-3$ and $C_{18: 2} n-6$. The decrease in plasma content of $C_{18: 3} n-3$ could be detrimental, since it is the precursor of the n-3 FA family, for which the cardio-protective properties have been well established (De Lorgeril and Salen, 2004).

The main eicosanoid secreted by endothelial cells of aorta, namely $\mathrm{PGI}_{2}$, is known to inhibit platelet aggregation and to act as a vasodilator, while TXA2, the primary eicosanoid formed by platelets, induces platelet aggregation and act as a vasoconstrictor (Torres-Duarte and Vanderhoek, 2003). These two antagonist eicosanoids are both end products of the enzymatic oxidation of $C_{20: 4} n-6$, regulated by the cyclooxygenase-2 enzyme (COX-2). Consequently, a low level of $\mathrm{PGl}_{2}$ coupled with a high level of $\mathrm{TXA}_{2}$ in plasma have been related to thrombosis and ischemia (Oates et al., 1988). Feeding the T11-CLA butter did not affect the plasma levels of $\mathrm{PGI}_{2}$ and $\mathrm{TXA}_{2}$ compared with the $S$ butter in the present study, whereas in vitro studies have shown that cis9, trans-11 CLA inhibited the formation of thromboxane in washed human platelets (Truitt et al., 1999), and decreased the production of $\mathrm{PGI}_{2}$ by human aortic endothelial cells (Eder et al., 2003). In a recent study, a cis-9, trans-11 CLAenriched butter oil has been shown to down-regulate the expression of the COX-2 gene in the aorta of cholesterol-fed hamsters when compared with a standard butter oil, suggesting an anti-inflammatory effect (Valeille et al., 2005). Furthermore, the authors also reported a reduced expression of the vascular cell adhesion molecule 1 (VCAM1) gene in aorta from hamsters fed the cis-9, trans-11 CLAenriched butter oil, suggesting a reduced infiltration of lipids into the aorta wall.

In line with this, feeding the T11-CLA butter could have protected against atherosclerosis development in the present study, since two-thirds of the rabbits fed this diet did not show any fatty streak in aorta, while only one rabbit among the two other diets did not show any lipid deposition. However, this beneficial effect did not reach the significance between the T11-CLA and the $S$ diets. The dietary intake of cis-9, trans-11 CLA was of about $0.2 \%$ of the diet, and is in the range $(0.05$ to $0.5 \%)$ of the dietary concentrations of a synthetic CLA-mixture (cis-9, trans-11 and trans-10, cis-12 CLA, in equal proportions) that have been shown to reduce the severity of lesions in arch and thoracic aorta in rabbits (Kritchevsky et al., 2002). Furthermore, the dietary intake of trans- $11 \mathrm{C}_{18: 1}(0.5 \%$ of the diet) could constitute a potential precursor pool for the formation of 
Roy, Chardigny, Bauchart, Ferlay, Lorenz, Durand, Gruffat, Faulconnier, Sébédio and Chilliard

cis-9, trans-11 CLA through the action of $\Delta 9$-desaturase in rabbit tissues, as already demonstrated in human (Turpeinen et al., 2002) and rodents (Santora et al., 2000; Corl et al., 2003).

Compared with the $S$ butter, the T11-CLA butter did not modify the cholesterolemia. This is in accordance with previous studies comparing a standard butter with a cis-9, trans-11 CLA-enriched butter in hamsters (Valeille et al., 2005), or comparing a CLA mixture-supplemented diet with a non-supplemented diet in rabbits (Kritchevsky et al., 2002 and 2004) and hamsters (Mitchell et al., 2005). However, several other studies with hamsters reported a decrease in cholesterolemia, when a trans-11 $\mathrm{C}_{18: 1}+$ cis-9, trans-11 CLA-rich butter was compared with a standard butter (Lock et al., 2005), or when a CLA mixture-supplemented diet was compared with a non-supplemented diet (Nicolosi et al., 1997; Wilson et al., 2000). It should be noted that studies testing the effects of a CLA-mixture supplementation on cholesterolemia in humans also generally gave unclear results (reviewed by Terspstra (2004)). The positive correlation between the cholesterolemia and the severity of fatty streak in aorta observed in the present study in rabbits corroborates the well established atherogenic effect of hypercholesterolemia in humans (Libby et al., 2000). Moreover, the rabbits fed the T11-CLA butter resulted in lower plasma concentrations of HDL and HDL-C than the rabbits fed the $S$ butter (without effect neither on the non-HDL to HDL ratio, nor on the LDL-C to HDL-C ratio). The HDL-C-lowering effect of the T11-CLA butter was not reported in previous animal studies (Kritchevsky et al., 2002; Lock et al., 2005; Mitchell et al., 2005), although non-significant decreases in HDL-C have been reported in several studies in humans receiving a CLA mixture (cis-9, trans-11 CLA and trans-10, cis-12 CLA) for 4 to 12 weeks (reviewed by Terpstra (2004)). Although high plasma levels of HDL-C have been associated with a reduced incidence of CVD in humans (review of Barter et al., 2003), the lower levels of HDL-C in the plasma from rabbits fed the T11-CLA butter was not associated with an increased aortic lipid infiltration, in the present study.

The curvilinear correlation between the severity of aortic lipid deposition and the non-HDL-C to HDL-C ratio observed in the present study matches with the linear correlation reported by Valeille et al. (2005) in hamsters between CE deposition in aorta and non-HDL-C to HDL-C ratio. This adds evidence for non-HDL-C to $\mathrm{HDL}-\mathrm{C}$ ratio as a risk factor of atherosclerosis, and CE deposition as the major part of the lipid infiltration in aorta wall. Furthermore, the positive correlation between plasma TC to $\mathrm{HDL}-\mathrm{C}$ ratio and lipid deposition in aorta wall observed in rabbits is in accordance with the fact that this ratio has been recently considered as the most representative risk factor of CVD in humans (Mensink et al., 2003).

The correlations between the severity of fatty streak areas and either the TC content of the liver or the plasma cholesterol concentrations observed in rabbits corroborate data from experiments carried out with mice lacking liver
$X$ receptors (LXR) gene. Liver $X$ receptors are members of the nuclear receptor family of lipid-sensing transcription factors (Chawla et al., 2001) and have emerged as key regulators of cholesterol and lipid metabolism (Barish and Evans, 2004). The hepatic and intestinal LXR genes regulate the cholesterol homeostasis by controlling intestinal absorption, reverse cholesterol transport, endogenous cholesterol synthesis and catabolism, and excretion into the bile (Millatt et al., 2003). Mice genetically lacking LXR $\alpha$ develop marked hepatic steatosis and hypercholesterolemia when fed a cholesterol-containing high-fat diet (Peet et al., 1998) and show increased formation of aortic foam cells, which are precursors for atherosclerosis (Schuster et al., 2002). Thus, the atherogenic diets offered to the rabbits in the present study could have mimicked the absence of LXR in genetically deficient mice, and led to comparable symptoms.

The T11-CLA butter did not modify triglyceridemia compared with the $S$ butter, as reported in rabbits (Lee et al., 1994; Kritchevsky et al., 2002 and 2004) and hamsters (Lock et al., 2005; Mitchell et al., 2005). In addition, the increase in triglyceridemia between 6 and 12 weeks of feeding the $S$ butter was not observed in the rabbits fed the T11-CLA butter. Additionally, feeding the T11-CLA butter for 12 weeks resulted in a slightly higher TG deposition in the liver of the rabbits. Thus, the stability of triglyceridemia between 6 and 12 weeks of feeding the T11-CLA butter suggests that this diet could have limited the hypertriglyceridemia, by increasing the TG deposition in the liver.

The positive close relationship between the triglyceridemia and the severity of lipid deposition in the aorta of rabbits was already reported in hamsters (Mangiapane et al., 1999) and is in accordance with the fact that hypertriglyceridemia is an independent risk factor of atherosclerosis in human (Hennig et al., 2001).

One key result of the present study is that the consumption of the T10 butter had a more detrimental effect than the T11-CLA butter on fatty streak areas, although not differing from the $S$ butter. When the two experiments study are taken together, the T10 butter resulted in higher plasma levels of VLDL-C and non-HDL particles, and nonHDL to HDL ratio than the $S$ butter. Moreover, the T10 butter increased cholesterolemia and plasma levels of LDL-C, compared with the T11-CLA butter. This suggests that the T10 butter resulted in impaired lipoprotein and cholesterol metabolism. Owing to the deep dyslipidemia and dyslipoproteinemia already observed in the T10 group at the end of experiment 1 ( 6 weeks), the altered cholesterolemia and lipoproteinemia could have been the cause of the decrease in dietary intake observed in two rabbits of the T10 group during week 12 of the experiment 2 . As the effects on lipe$\mathrm{mia}$, lipoproteinemia and atherosclerosis of the trans-10 $\mathrm{C}_{18: 1}$, either as purified isomer or present at high level in a dietary product, have never been tested before, this study is the first to report experimental data on the putative effects of this trans FA. 
The correlations observed in the present study between the severity of lipid infiltration in the aorta wall and several risk factors of CVD, including triglyceridemia, cholesterolemia, the non-HDL-C to HDL-C and TC to HDL-C ratios, add new evidence to consider the cholesterol-induced atherosclerosis in rabbit as a suitable and representative model for studying diet-induced dyslipidemia and atherosclerosis in humans.

\section{Conclusion}

The results of this study suggest that the trans-11 $\mathrm{C}_{18: 1}+$ cis-9, trans-11 CLA-rich butter included into an atherogenic diet for 12 weeks decreased, compared with the trans-10 $C_{18: 1}$-rich butter and, to a lesser extent, to the standard butter, the occurrence of atherosclerosis, and increased liver TG content without significantly affecting lipemia and lipoproteinemia, in rabbits (except a lowering effect in the plasma HDL particles and HDL-C levels). The trans-10 $C_{18: 1}$-rich butter caused impaired plasma cholesterol metabolism and non-HDL levels, compared with the standard butter, which probably led to decreased dietary intake in one-third of the rabbits in experiment 2. However, further studies involving larger number of rabbits, longer experimental period and/or lower level of dietary cholesterol, are warranted to confirm both the putative atheroprotective role of the couple trans-11 $\mathrm{C}_{18: 1}+$ cis-9, trans-11 CLA, and the suggested negative influence of a trans-10 $C_{18: 1}$-rich butter on experimental atherosclerosis, plasma lipid and lipoprotein profiles.

\section{Acknowledgements}

This work was funded by the INRA 'Micronutrients in animal products: CLA-B12' project, managed by Jean-Louis Sébédio and Dominique Bauchart, and 'AQS 2001' project managed by Michel Doreau. The authors would like to thank S. Almanza, B. Buteau, S. Grégoire and L. Leclere for technical assistance.

\section{References}

Barish GD and Evans RM 2004. PPARs and LXRs: atherosclerosis goes nuclear. Trends in Endocrinology and Metabolism 15, 158-165.

and Future Forum Editorial Board Barter $\mathrm{P}$, Kastelein J, Nunn A and Hobbs R 2003. High density lipoproteins (HDLs) and atherosclerosis; the unanswered questions. Atherosclerosis 168, 195-211.

Bartlett GR 1959. Phosphorus assay in column chromatography. Journal of Biological Chemistry 234, 466-468.

Bauchart D, Durand D, Laplaud PM, Forgez P, Goulinet S and Chapman MJ 1989. Plasma lipoproteins and apolipoproteins in the preruminant calf, Bos spp: density distribution, physiochemical properties, and the in vivo evaluation of the contribution of the liver to lipoprotein homeostasis. Journal of Lipid Research 30, 1499-1514.

Bauman DE, Barbano DM, Dwyer DA and Griinari JM 2000. Technical note: production of butter with enhanced conjugated linoleic acid for use in biomedical studies with animal models. Journal of Dairy Science 83, 2422-2425.

Chawla A, Repa JJ, Evans RM and Mangelsdorf DJ 2001. Nuclear receptors and lipid physiology: opening the X-files. Science 294, 1866-1870.

Chilliard $Y$ and Ferlay A 2004. Dietary lipids and forages interactions on cow and goat milk fatty acid composition and sensory properties. Reproduction Nutrition Development 44, 467-492.

Christie WW, Sébédio J-L and Juanéda P 2001. A practical guide to the analysis of conjugated linoleic acid. Inform 12, 147-152.
Corl BA, Barbano DM, Bauman DE and Ip C 2003. Cis-9, trans-11 CLA derived endogenously from trans-11 18:1 reduces cancer risk in rats. Journal of Nutrition 133, 2893-2900.

De Lorgeril M and Salen P 2004. Use and misuse of dietary fatty acids for the prevention and treatment of coronary heart disease. Reproduction Nutrition Development 44, 283-288.

Eder K, Schleser S, Becker K and Korting R 2003. Conjugated linoleic acid lower the release of eicosanoids and nitric oxide from human aortic endothelial cells. Journal of Nutrition 133, 4083-4089.

Faulconnier Y, Roy A, Ferlay A, Chardigny J-M, Durand D, Lorenz S, Gruffat D and Chilliard $Y$ 2006. Effect of dietary supply of butters rich either in trans10-18:1 or in trans-11-18:1 plus cis-9, trans-11-18:2 on rabbit adipose tissue and liver lipogenic activities. British Journal of Nutrition 96, 461-468.

Folch J, Lees M and Sloane Stanley GH 1957. A simple method for the isolation and purification of total lipids from animal tissues. Journal of Biological Chemistry 226, 497-509.

Hennig B, Toborek M and McClain CJ 2001. High-energy diets, fatty acids and endothelial cell function: implications for atherosclerosis. Journal of American College of Nutrition 20, 97-105.

Hodgson JM, Wahlqvist ML, Boxall JA and Balazs ND 1996. Platelet trans fatty acids in relation to angiographically assessed coronary artery disease. Atherosclerosis 120, 147-154.

Ip C, Banni S, Angioni E, Carta G, McGinley J, Thompson HJ, Barbano D and Bauman D 1999. Conjugated linoleic acid-enriched butter fat alters mammary gland morphogenesis and reduces cancer risks in rats. Journal of Nutrition 129, 2135-2142.

Kritchevsky D, Tepper SA, Wright S and Czarnecki SK 2002. Influence of graded levels of conjugated linoleic acid (CLA) on experimental atherosclerosis in rabbits. Nutrition Research 22, 1275-1279.

Kritchevsky D, Tepper SA, Wright S, Czarnecki SK, Wilson TA and Nicolosi RJ 2004. Conjugated linoleic acid isomers effects in atherosclerosis: growth and regression of lesions. Lipids 39, 611-616.

Lee KN, Kritchevsky D and Pariza MW 1994. Conjugated linoleic acid and atherosclerosis in rabbits. Atherosclerosis 108, 19-25.

Leplaix-Charlat L, Bauchart D, Durand D, Laplaud PM and Chapman MJ 1996. Plasma lipoproteins in preruminant calves fed diets containing tallow or soybean oil with and without cholesterol. Journal of Dairy Science 79, 12671277.

Libby P, Aikawa M and Schönbeck U 2000. Review: cholesterol and atherosclerosis. Biochimica et Biophysica Acta 1529, 299-309.

Lock AL, Horne CAM, Bauman DE and Salter AM 2005. Butter naturally enriched in conjugated linoleic acid and vaccenic acid alters tissue fatty acids and improves the plasma lipoprotein profile in cholesterol-fed hamsters. Journal of Nutrition 135, 1934-1939.

Mangiapane EH, McAteer MA, Benson GM, White DA and Salter AM 1999. Modulation of the regression of atherosclerosis in the hamster by dietary lipids: comparison of coconut oil and olive oil. British Journal of Nutrition 82, 401-409.

Mensink RP, Zock PL, Kester ADM and Katan MB 2003. Effects of dietary fatty acids and carbohydrates on the ratio of serum total to HDL cholesterol and on serum lipids and apolipoproteins: a meta-analysis of 60 controlled trials. American Journal of Clinical Nutrition 77, 1146-1155.

Millatt L, Bocher V, Fruchart JC and Staels B 2003. Liver X receptors and the control of cholesterol homeostasis: potential therapeutic targets for the treatment of atherosclerosis. Biochimica et Biophysica Acta 1632, 107-118.

Mitchell PL, Langille MA, Currie DL and McLeod RS 2005. Effect of conjugated linoleic acid isomers on lipoproteins and atherosclerosis in the Syrian golden hamster. Biochimica et Biophysica Acta 1734, 269-276.

Nicolosi RJ, Roger EJ, Kritchevsky D, Scimeca JA and Huth PJ 1997. Dietary conjugated linoleic acid reduces plasma lipoproteins and early aortic atherosclerosis in hypercholesterolemic hamsters. Artery 22, 266-277.

Oates JA, Fitzgerald GA, Branch RA, Jackson EK, Knapp HR and Roberts LJ 1988. Clinical implications of prostaglandin and thromboxane $A_{2}$ formation. New England Journal of Medicine 319, 689-698.

Peet DJ, Janowski BA and Mangelsdorf DJ 1998. The LXRs: a new class of oxysterol receptors. Current Opinion in Genetics and Development 8, 571575.

Precht D and Molkentin J 1996. Rapid analysis of the isomers of trans-octadecenoic acid in milk fat. International Dairy Journal 6, 791-809. 


\section{Roy, Chardigny, Bauchart, Ferlay, Lorenz, Durand, Gruffat, Faulconnier, Sébédio and Chilliard}

Roy A, Ferlay A and Chilliard Y 2006. Production of butter fat rich in trans10-C18:1 for use in biomedical studies in rodents. Reproduction Nutrition Development 46, 211-218.

Santora JE, Palmquist DL and Roehrig KL 2000. Trans-vaccenic acid is desaturated to conjugated linoleic acid in mice. Journal of Nutrition 130, 208-215.

Schuster GU, Parini P, Wang L, Alberti S, Steffensen KR, Hansson GK, Angelin $B$ and Gustafsson JA 2002. Accumulation of foam cells in liver $X$ receptordeficient mice. Circulation 106, 1147-1153.

Sébédio J-L, Juanéda $\mathrm{P}$, Grégoire $\mathrm{S}$, Chardigny J-M, Martin J-C and Giniès C 1999. Geometry of conjugated double bonds of CLA isomers in a commercial mixture and in their hepatic 20:4 metabolites. Lipids 34, 1319-1325.

Statistical Analysis Systems Institute 1985. SAS user's guide, statistics (fifth edition). SAS Institute Inc., Cary, NC, USA.

Terpstra AH 2004. Effect of conjugated linoleic acid on body composition and plasma lipids in humans: an overview of the literature. American Journal of Clinical Nutrition 79, 352-361.

Toomey S, Roche H, Fitzgerald 0 and Belton 0 2003. Regression of pre-established atherosclerosis in the apoE $-I-$ mouse by conjugated linoleic acid. Biochemical Society Transactions 31, 1075-1079.
Torres-Duarte AP and Vanderhoek JY 2003. Conjugated linoleic acid exhibits stimulatory and inhibitory effects on prostanoid production in human endothelial cells and platelets. Biochimica Biophysica Acta 1640, 69-76.

Truitt A, McNeill G and Vanderhoek JY 1999. Antiplatelet effects of conjugated linoleic acid isomers. Biochimica Biophysica Acta 1438, 239-246.

Turpeinen AM, Mutanen M, Aro A, Salminen I, Basu S, Palmquist DL and Griinari JM 2002. Bioconversion of vaccenic acid to conjugated linoleic acid in humans. American Journal of Clinical Nutrition 76, 504-510.

Valeille K, Férézou J, Amsler G, Quignard-Boulangé A, Parquet $M$, Gripois $D$, Dorovska-Taran V and Martin J-C 2005. A cis-9,trans-11-conjugated linoleic acid-rich oil reduces the outcome of atherogenic process in hyperlipidemic hamster. American Journal of Physiology, Heart and Circulatory Physiology 289, H652-H659.

Wahle KW, Heys SD and Rotondo D 2004. Conjugated linoleic acids: are they beneficial or detrimental to health? Progress on Lipid Research 43, 553-587.

Wilson TA, Nicolosi RJ, Chrysam M and Kritchevsky D 2000. Conjugated linoleic acid reduces early aortic atherosclerosis greater than linoleic acid in hypercholesterolemic hamsters. Nutrition Research 20, 1795-1805. 